The author replies

\title{
Replica a los comentarios
}

Agradezco, ante todo, los sesudos comentarios. Ha sido un honor, en primer lugar, haber sido invitada por los editores a escribir este artículo y posteriormente haber contado con la lectura de tan connotados colegas para propiciar un diálogo. Debido a la multiplicidad de temas por ellos abordados, podré solo referirme someramente a algunos que seleccioné para tratarlos transversalmente, y manifestarébrevementemi discrepancia con algunas interpretaciones de mi artículo.

Muy acertados me parecen los aspectos que Cristiani Vieira Machado sintetiza como rasgos comunes delas experiencias de Chile, Colombia y M éxico que abarqué en mi análisis. A saber, que con estas formas de ampliación de la cobertura ha persistido la fragmentación y la heterogeneidad de los sistemas de salud, se ha profundizado la segmentación del aseguramiento, y se ha expandido la oferta privada (cabe aquí insertar las razones de Román Vega Romero, quien aduce que las segmentaciones y fragmentaciones del sistemacolombiano están precisamente en la base de su falta de sostenibilidad financiera), y que la adopción de planes explícitos de beneficios evidencia serias limitaciones que deben ser consideradas en otros países donde se discute acerca de la posibilidad de adoptar listas explícitas de acciones de salud.

Por su parte, promover la adopción de seguros voluntarios desalud (aspecto comentado por 
Román Vega Romero), como se advierte actualmenteen Colombia y en Chile, refuerza sin duda la privatización del aseguramiento, quea nuestro juicio coarta una diversificación de riesgos adecuada y estable, cuyo financiamiento requiere a tal fin -como ya lo hemos planteado en diversas oportunidades- orientarse por el principio de solidaridad, sea mediante cotizaciones obligatorias o bien con cargo al presupuesto nacional.

Todo ello puede ponerse en consonancia con la idea de Javier Rey del Castillo de que en la mayoría de los países ha habido una tendencia a establecer sistemas diferenciados de protección para distintos grupos de población, y con la advertencia deSonia Fleury de quela integración de los sistemas contributivos y no contributivos por sí sola no resuelve las exclusiones y las desigualdades, ya que es fundamental el incremento de los recursos, la progresividad del gasto y su acción contracíclica. Lograr además la integración de los sistemas, por cierto, es un difícil reto en la región cuando se da en el marco de combinaciones público privadas queno necesariamenteconforman un marco de incentivos adecuados a tal efecto - como lo ha señalado Celia Almeida- sino que promueven queestos entes actúen como aseguradores o prestadores "puros", carentes de responsabilidades respecto de diversos bienes públicos, y desprovistos de regulaciones claras que aseguren el efectivo goce del derecho a la salud de los ciudadanos.

Las serias limitaciones de los planes explícitos, según Vieira M achado, se relacionan con su orientación "gerencial", que subestima los altos costos de transacción y la complejidad política que le son inherentes y que pueden derivar en una al ta judicialización de la política social. En un contexto semejante, Román Vega Romero advierte acerca de las decisiones tecnocráticas y de la participación ciudadana limitada queson propias de los métodos de priorización asociados con los paquetes de ben eficios y con la definición de servicios explícitamente garantizables y no garantizables y de las tensiones políticas y financieras acarreadas por el incumplimiento de la progresiva confluencia de coberturas.

Se advierte entonces, como lo ha afirmado Celia Almeida respecto de las agendas de reforma contemporáneas, que los principios de solidaridad, equidad y universalidad, presentes en la formulación de las reformas evidencian serios trade offs a la hora de su operacionalización.

En tal sentido, pueden considerarse las consecuencias indeseables de los términos genéricos y amplios de un supuesto constitucional de un "derecho a la salud" que plantea Javier Rey del Castillo y la conveniencia de regular este derecho en términos de "protección de la salud", y remitir la forma de ejercerlo a las leyes de desarrollo constitucional, y a concretar el derecho universal en términos de creación de un servicio público de salud y el establecimiento de condiciones similares de acceso a sus servicios.

De allí las sendas limitaciones para avanzar en la superación de las desigual dades estructurales en la perspecti va de una ciudadanía más plena asociada con el ejercicio del derecho a la salud, y la necesidad de plantear la universalidad desde una perspectiva distinta a la adoptada por tesis tales como el universalismo básico o la focalización reduccionista que en ocasiones ha plagado la política social.

Coincido con Fleury respecto de la necesidad de impulsar políticas de aseguramiento solidarias versusla individual ización de riesgos, asunto que he abordado en otras oportunidades ${ }^{1}$, y comparto su preocupación acerca del elevado gasto privado, considerando tanto su regresividad, como su cuestionada eficacia. Un aspecto adicional, muy preocupante en el caso de América Latina, es la magnitud del gasto en salud "reprimido"; es decir, aquel que no pueden efectuar los hogares pobres pese a sus vastas necesidades insatisfechas en esta materia, aspecto tocado en el capítulo $\mathrm{V}$ de los O bjetivos de desarrollo del milenio².

Un aspecto -que no era el propósito de mi artículo- pero que resalta prácticamente en los análisis de todos los comentaristas es la necesidad de analizar la magnitud y orientación del gasto en salud a la luz del papel de la industria farmacéutica y la de otras tecnologías sanitarias, de las ganancias de las empresas aseguradoras y las prestadoras de servicios, y de las conductas de riesgo moral tanto respecto de la fijación de precios y tarifas, como de la calidad brindada. Emerge además como un objeto interesante de investigación el precisar cómo estos intereses se han traducido específicamente en las instituciones del sector salud y en las coberturas. También la necesidad de evidenciar la escasa capacidad regulatoria con la que cuentan los Estados latinoamericanos para velar por la eficiencia del gasto y para actuar contra el descremedel mercado. Otro aspecto importante es indagar en el vínculo entre las reformas sanitarias y la descentralización en los países. Las evidencias empíricas precisas de investigaciones que ahonden en estos temas serán fundamentales para, con las palabras deFleury, impugnar opciones trágicas respecto de la universalización. 
Finalmente debo subrayar que bien lejos de mi perspectiva de análisis estaría plantear que las reformas tratadas hayan sido animadas por la simpleampliación dela cobertura. Estereduccionismo angelical delos objetivos traduciría-cuando menos- una perspectiva ingenua en esta materia que, sin embargo, parecen imputarme Núria Homedes y Antonio U galde, a pesar del intento que realicé por indagar en las racionalidades múltiples en quetuvieron lugar esas ampliaciones de cobertura, dados los marcos institucionales y políticos específicos de los tres países.

En el mismo sentido, quisiera resaltar que tampoco he postulado que las experiencias de garantías en marcha constituyan la plenitud de la universalidad, ni quelas restricciones definanciamiento justifiquen tales medidas, ni que los avances en cobertura aludidos hayan Ilevado a la superación de las desigualdades en salud, como pudiera aquí y allá sugerirse.

Afirmo enérgicamente que la universalidad es un horizonte imposible de lograr de buenas a primerasy hacia el queinevitablemente se avanza solo en medio de diversas restricciones políticas y financieras, y en el marco de correlaciones de poder diversas. En ese sentido, los reparos respecto de la judicialización del derecho que he manifestado apuntan a los excesos en que sepuede incurrir, a las restricciones de la casuística y a los sendos impactos políticos y financieros que están en juego. N o se trata de desechar el recurso judicial como camino para queel derecho se haga efectivo, ni de desconocer su relevancia ante diversos obstáculos en el camino de la equidad, sino de señalar sus complejidades, a la luz de una vastajurisprudencia que setieneahora a la mano y que provee elementos empíricos de los que se carecía veinte años atrás. Pero dejo en manos de los lectores juzgar si mis argumentos sobre la judicialización de los derechos pueden así ser vistos, o si es pertinente etiquetarlos como un ropaje conceptual más sofisticado para un ideario neoliberal.

\section{Referencias}

1. Sojo A. Vulnerabilidad social, aseguramiento y diversificación de riesgos en América Latina y el Caribe. Revista CEPAL 2003; 80:121-140. [acceso 2011 mayo 11]. Disponible en: http://www.eclac.org/ publicaciones/xml/7/19367//cg2204e-Sojo.pdf

2. CEPAL. El gasto de bolsillo en salud: evidencia de desigualdades profundas. En: Objetivos de desarrollo del milenio: la progresión hacia el derecho a la salud en América Latina y el Caribe. [acceso 2011 mayo 11]. Disponible en: http://www.eclac.cl/cgibin/getProd.asp?xml=/publicaciones/xml/4/33064/ P33064.xml\&xsl=/tpl/p9f. xsl\&base=/tpl/topbottom.xsl 